\title{
ARTIGOS
}

\section{QUANDO AS CRIANÇAS VIADAS INTERPELAM A DOCÊNCIA}

\author{
Paulo Henrique de Queiros NOGUEIRA \\ Universidade Federal de Minas Gerais - UFMG \\ Belo Horizonte,Minas Gerais, Brasil \\ pauloqn@ufmg.br \\ ORCID https://orcid.org/0000-0001-8073-1214
}

Resumo: O presente ensaio se propõe a pensar as relações de gênero e aspectos da diversidade sexual a partir das contribuições de um episódio televisivo, um texto de Eve Sedgwick e outro de Giancarlo Cornejo: enunciações em torno dos meninos efeminados. Postulamos que nos debruçarmos sobre as "crianças viadas" pode nos ajudar a compreender as hierarquias de gênero que provocam e sustentam as assimetrias entre distintas posições. Assim, a partir desse analisador, interroga-se a escola e a formação de professores e professoras para pensarmos como nos posicionarmos frente a essas crianças como expressões da diferença.

Palavras-chave: Diversidade sexual, Escola, Formação de professores

\section{WHEN QUEER CHILDREN QUESTION TEACHERS}

\begin{abstract}
The present essay proposes as reflection on gender relationships and aspects of sexual diversity, starting with the input from a television episode, a text by Eve Sedgwick and another by Giancarlo Cornejo, two pieces by visual artist BiaLeite, and Internet posts by journalist Iran Giusti: enunciations about effeminate young boys. We postulate that analyzing so-called "queer children" can help us understand the gender hierarchies that cause and sustain the asymmetry between different social positions. Thus, starting with this line of analysis, school and the training of teachers are put into question, in order to reflect on how one should position oneself regarding those children as expressions of difference.
\end{abstract}

Keywords: Sexual diversity, School, Training of teachers

\section{CUANDO LOS NIÑOS MARICONES INTERROGAN LA DOCENCIA}

Resumen: El presente ensayo se propone pensar las relaciones de género y aspectos de la diversidad sexual a partir de las contribuciones de un episodio televisivo, um texto de EveSedgwick y otro de Giancarlo Cornejo: enunciaciones sobre niños afeminados. Proponemos que abordar a los "niños maricones" puede ayudarnos a compreender las jerarquías de género que causan y mantienen asimetrías entre distintas posiciones. Por lo tanto, desde este analizador, se les se interroga a la escuela y a la formación de los docentes para pensar em como nos posicionarnos frente a esos niños como expresiones de la diferenrecia.

Palabras-clave : Diversidad sexual, Escuela, Formación de docentes 


\section{autêntica}

DOI https://doi.org/10.31639/rbpfp.v12i24.341

\section{Introdução}

Iniciamos esse ensaio com a exposição de um suicídio retratado num programa de televisão e o fazemos pela força persuasiva que esse relato carrega ao nos dizer de como a vida é bastante frágil e deve ser cuidada. Não queremos enaltecer ou generalizar essa atitude, muito ao contrário, o objetivo é tomá-lo como vocalizador de uma experiência muitas vezes marginal que é a presença de "crianças viadas" nos estabelecimentos escolares.

Em que a expressão "criança viada" é cunhada por Iran de Jesus Giusti, jornalista e ativista gay, que, em 2012, criou um Tumblr denominado "criança viada", reunindo fotos dele e de amigos retratando expressões de gênero em desacordo às expectativas sociais: meninos efeminados e meninas masculinizadas. O uso do termo é aqui utilizado por sua força êmica percebida, por exemplo, em sua apropriação pela artista plástica Bia Leite ao nomear suas obras com esse epíteto na exposição "Queer museu - Cartografias da Diferença na Arte Brasileira", em 2015, alvo de proibição no contexto que antecedeu ao golpe de 2016.

Assim, tomamos o programa Profissão Repórter da Rede Globo, no ano de 2009, que, em um de seus episódios, retratou o suicídio de um adolescente gay, assim nomeado pela reportagem, por ser lido pelos colegas e outras crianças como uma criança viada, um menino efeminado.

O objetivo do episódio era fazer um retrato das escolas públicas que se encontram na periferia das grandes cidades e, entre os diversos aspectos abordados, a equipe de reportagem deparou-se com o caso de um jovem de quatorze anos, lago, um estudante aplicado e meigo, assim caracterizado pela reportagem, que, não suportando mais as violências homofóbicas sofridas, resolve tirar sua própria vida.

É possível encontrar especificamente esse episódio do programa na internet, entretanto, não traremos o link, nem referências mais precisas, para preservar as pessoas envolvidas e por acreditar que, mesmo após tantos anos, a dor do suicídio ainda possa atingir os familiares pela perda, fazendo reviver essa dor; assim como expor, mais uma vez, a escola e seus profissionais que teriam que lidar, não apenas com a ausência de lago, mas com as repercussões de uma possível omissão no cotidiano escolar quando a integridade de lago se viu ameaçada pela violência homofóbica. Assim, apenas transcrevo as falas dos envolvidos no episódio aqui indicado, preservando o nome verdadeiro de lago, como derradeira homenagem a ele no reconhecimento que cerca a fragilidade de uma criança viada - conforme discutiremos no decorrer do texto.

A reportagem escuta familiares de lago e profissionais da escola que lhe dizem de alguns aspectos dessa violência que the foi impingida:

Diza mãe de lago:

- Em qualquer lugar ele era agredido, tanto na rua, na escola, com a minha mãe mesmo...

- Ele ia pra escola, os meninos ficavam zombando dele, né, chamava ele de bicha, tudo. E foi criando aquilo na cabecinha dele. Dizia: 'Vó, um dia vô me matar', (eu) falava: 'Ocê não vai fazer isso não'. - dizia a avó de lago.

- Ele escreveu essa carta: 'Mãe, eu te amo. A vó Lia é tudo pra mim e a tia Luiza também. Eu amo as minhas tias, mas a tia Luiza é tudo para mim. E quando eu olho para ela, eu sinto muita vontade de chorar e de abraçar ela também. Mãe, eu não sei explicar porque eu estou fazendo isso. -fala a tia de lago, muito emocionada, lendo a carta deixada por ele, enquanto imagens de fotografias e vídeos de lago, em diferentes momentos, são exibidas.

- Você via seu irmão na hora do intervalo, por exemplo. - perguntouareportagem ao irmão de lago. 


\section{autêntica}

- Via...

- O que é que acontecia?

- Os moleque ia bater nele, aí, vinha um monte de moleque, aí, grande, bater nele. Aí, eu disse: 'Olha aí, o meu irmão tá apanhando, aí, os moleque tão batendo nele, aí. Aií ela, 'eu não tenho nada a ver com isso, as briga é de vocês'.

- A professora falou isso?

- Professora.

Na escola, o repórter pergunta a vice-diretora:

- Ele não se enturmava muito?

- Isso, ele ficava quieto, na dele, né, mas,já, eu acredito que já havia algumacoisa de diferente.

- A família alguma vez se queixou?

- Não.

- Como é que a senhora, diretora, e os professores lidam com isso?

- A gente tá tentando trabalhar esse lado, mas tá difícil.

Esse caso tem uma duração inferior a dois minutos e quarenta segundos, sendo que quarenta e cinco segundos são destinados aos bastidores da reportagem, e o caso do suicídio se perde nos contextos de violências que as escola vivenciam. Esse suicídio é apenas mais um índice de que as escolas públicas estão sobrecarregadas de constrangimentos e senões quanto à sua organização e capacidade de fazer frente aos desafios que enfrenta, a homofobia é apenas mais uma dessas dimensões.

E é a inconsistência das informações, portanto, que não nos permite extrapolar o diálogo acima, bastante curto, mas veemente quanto a questões dessa ordem tão delicadas e aflitivas para familiares e escola.

lago era visto como um menino efeminado ${ }^{1}$, uma criançaviada, seu corpo dizia da precariedade ${ }^{2}$ que cercava sua existência, do desconforto que a sua sexualidade trazia para os que estavam a seu redor, de quanto, simultaneamente, aquele corpo fragilizado era perturbador de uma ordem heterossexista que, enfim,levou-o a cometer suicídio na tentativa de lidar com questões que para ele, uma criança de quatorze anos, revelavam-se insuportáveis.

E aqui há duas dimensões que devem ser apontadas, ao nos propor distanciarmos da experiência como relatada no programa de televisão, com seus cortes e edições a priorizar um olhar, uma abordagem, alguns sujeitos - não devemos esquecer que a mídia, principalmente a grande imprensa, constrói narrativa.

O que aqui nos propomos é pensar as crianças viadas e como a existência desses meninos efeminados pode nos servir como um analisador ${ }^{3}$ da escola a aportar sentidos para a formação de professores em que se leve em conta a diversidade sexual e de gênero.

1 A relação entre gênero, sexo e orientação sexual - apenas para citar três aspectos aleatórios, mas que para nós, modernos, são definidores de uma tríade articuladora de identidades a dizer quem somos e por onde nos movemos - é bastante complexa para ser aqui reduzida ao entendimento que "meninos efeminados" sejam necessariamente homossexuais. Ao longo da história, há possibilidades distintas de arranjar esses elementos conforme modelos autóctones de composição dessas ou outras variáveis. Iago, a rigor, não é homossexual, ser visto como uma criança viada não diz de homossexualidade irrefutavelmente. Havendo períodos na história social que homens efeminados tinham desejos por mulheres e, portanto, não seriam considerados homossexuais sob o nosso olhar. FOUCAULT (1990b), HALPERIN (2002) e WINKLER (1994).

2 Butler, em Vida Precária, 2009, diz como a precariedade é uma dimensão ética da vida em que o jogo especular do humano, inumano e humano impensável se encontra transpassado pela disputa de quem é reconhecido como digno, como tendo uma vida viável. A precariedade se inscreve, portanto, nas lógicas de reconhecimento por erodir a relação para com a alteridade e tratá-la como uma outridade não representável as demandas de igualdades.

3 O conceito de "analisador" emerge a partir das contribuições da análise institucional e da socioanálise e é caracterizado quando determinados fenômenos manifestam e evidenciam as estruturas subjacentes ao observado, permitindo-nos compreender as hierarquias implícitas ao manifesto. (HESS, 1975) 


\section{Primeira dimensão: o que se falha em oferecer a uma criança viada}

O primeiro elemento, trazido por Eve Sedgwick (1993), em seu artigo intitulado How to bring your kids up gay, é como as politicas públicas e a ciência estão permeadas por uma perspectiva heteronormativa em que as crianças efeminadas são marginalizadas por um paradigma no qual as expressões das homossexualidades masculinas, hiper valorizadas frente às lesbianidades, são hierarquizadas por construtos e representações da virilidade em que se efetiva, de fato, uma vigilância sobre essas identidades assentadasno binarismo de gênero: "Um problema grave com essa forma de distinguir gênero de sexualidade é que enquanto se desnaturaliza a escolha do objeto de desejo, renaturaliza-se radicalmente o gênero."(SEDGWICK, 1993, p. 73)

Ou seja, as crianças viadas, mesmo com um esforço nominal de se compreender sua orientação sexual como aceita e adequada, possuem suas expressões de gênero questionadas como inadequadas posto que o paradigma do aceitável está regulado por uma masculinidade viril que nortearia o que se espera das homoidentidades. Portanto, em um ato prestidigitador, o que aparentemente seria um ato de acolhimento da diferença, revela-se a reiteração de assimetrias sexuais a inferiorizar corpos masculinos efeminados.

O artigo, escrito em 1989 para uma conferência e publicado em 1993, inicia-se com um comentário acerca de um relatório produzido por um grupo de trabalho sobre suicídio juvenil do governo estadunidense. Em uma de suas seções, o relatório aponta o suicídio entre jovens gays como sendo de um número relevante e que, portanto, mereceria atenção do governo ao recomendar que se combatesse a discriminação advinda da orientação sexual.

Um dos diretores, que também é médico, ao ler o relatório, afirma que exatamente essa recomendação lhe parece inadequada e, apoiando-se em suas crenças pessoais e as do departamento, afirma que está fortemente comprometido a "promover valores familiares tradicionais" e que os pontos expressos no relatório estão contrários a essa perspectiva.

Logo após, a autora investiga como a psiquiatria e a psicologia do ego, no contexto estadunidense, tratam da questão das homossexualidades e, após realizar um arrazoado dos autores desses campos que se debruçaram sobre essa investigação, constata que o caráter homonormativo, adultocêntrico e clínico dessas abordagens sobre as homossexualidades na infância operam com um discurso normalizador das condutas em que essas crianças são vistas como desviantes ou patológicas. Autoriza-se agir, portanto, sobre elas com o intuito de diminuir a sua pretensa inadequação a partir de um modelo essencialista e paradigmático de sexualidade saudável destinada a homens homossexuais em que não há lugar para a criança viada.

\section{Eve Sedgwuick conclui:}

A renaturalização e o reforço da designação de gênero não são as piores noticias sobre essa nova psiquiatria de aceitação gay. O pior não é somente o que falha em oferecer, mas, sim, o que parece conceitualmente incapaz de oferecer, inclusive a mais mínima resistência ao desejo endêmico na cultura que nos rodeia e apoia: o desejo de que as pessoas gays não existam. (...) Não há nenhum discurso institucional importante que ofereça uma resistência firme a essa empreitada: nos Estados Unidos, especificamente, na maioria dos espaços do Estado, nas forças armadas, na educação, na lei, nas instituições penais, na igreja, na medicina e na cultura de massas a reforçam totalmente e sem questionamentos e com muito pouco receio inclusive de recorrer a violência invasiva. (SEDGWICK, 1993, p. 75 - 76) 
O que não se oferta a essas crianças são ambientes seguros, acolhedores, despidos dessas modalidades de cuidados psi que nada mais sinalizam do que a própria subalternização e precarização desses corpos a reiterar um desejo de supressão justamente daquilo que o transpassa que é a efeminização indesejada.

\section{Segunda dimensão: o que se oferece em demasia a uma criança viada}

O segundo elemento foi elaborado por Giancarlo Cornejo, pesquisador peruano, que, realizando uma auto-etnografia, relata sua experiência como uma criança viada.

O seu texto, intitulado La guerra declarada contra el niño afeminado: uma autoetnografía "queer,"relata como ele experienciou ser uma criança identificada e designada como efeminada junto a sua família e na escola.

A partir do texto de Eve Sedgwick, ele recupera suas memórias afetivas para entender como seu corpo e seus maneirismos foram vistos como inadequados para o que se espera dos comportamentos de meninos.

A primeira vez que escutou alguém chamá-lo de "maricón" tinha cinco anos e estava na escola, era aniversário de uma das meninas da turma de alunos. A professora distribuía os convites para uma festinha que ia acontecer posteriormente, o seu convite não estava lá, ele pergunta, a professora desconversa e lhe dá uma desculpa, uma "mentirilla".

Ele, então, vai diretamente perguntar à colega sobre o seu convite e o porquê dele não ter recebido. E "Ela me disse para não incomodá-la e que não tinha me convidado.Lembro-me que ela me deu um tapa e gritou 'bicha" para mim. Eu só pude chorar." (CORNEJO, 2020, 81)

Essa primeira nomeação o faz perceber que há uma inadequação em seu corpo, em sua sexualidade, em seu gênero, que o impede de ser visto como outro menino qualquer na turma. Ele era diferente, havia sinais em seu corpo que evidenciavam para os outros o que ele era, sem nem ele saber ou perceber como essas insígnias operavam nele, mas já assinalavam emblematicamente que, por ser uma criança viada, tratavam-se de marcas públicas, conhecidas por todos que compartilham as normas de gênero em que se convocam meninos para serem viris e performar em masculinidades condizentes com as expectativas que se depositam sobre seus corpos.

Aqui, ressalta-se, sob outro ponto de vista, o aspecto denunciado por Sedgwicksobre como, ao tratar da homossexualidade entre jovens, o que está em jogo é uma vigilância acirrada de como esses jovens, unicamente meninos, performam gênero. E ao recusar essa modalização vista como inadequada, reitera-se e incorpora-se o que se encontra disseminado pela cultura e pelas instituições do horror que a e feminização de corpos viris causa. Não se trata de orientação sexual, trata-se de uma violência de gênero que diagrama e encapsula determinados corpos masculinos assinalados como efeminados e os ameaça:

O que essa menininha viu, e que eu não tinha percebido até então, era minha posição precária. A linguagem de ódio torna evidente que a vida (linguística) da pessoa injuriada já era uma vida ameaçada de extinção. (CORNEJO, 2020, p. 82)

Essa efeminofobia/effeminophobia ${ }^{5}$ consistiria em um rebaixamento, uma precarização dos corpos efeminados imposto pelas assimetrias que atravessam as hierarquias sociais e tornam alguns corpos, inclusive, a principio, independentemente de sua orientação sexual, por performarem expressões de gênero consideradas inadequadas a seus corpos a partir das normas de gênero.

4 Maricón no original.

5 Em espanhol há um termo bastante sugestivo que é plumofobia para designar a rejeição, entre gays, de homens homossexuais efeminados. 


\section{autêntica}

DOI https://doi.org/10.31639/rbpfp.v12i24.341

Ela viria a acompanhar a Giancarlo na escola, em outras disciplinas como Educação Física, ou junto aos serviços de acompanhamento pedagógico, em que sua performance se tornava um problema, mesmo sendo um bom aluno.

E a escola, como instituição educativa, espraiava esses cuidados e receios em torno a ele ao convocar os seus pais para dizer de que havia algo errado, havia algo não esperado, e que algo deveria ser feito para que se pudesse tratar melhor aquilo que era visto como um desvio e uma patologia.

As idas a terapias psicológicas - uma saída sempre esperada para certos estratos sociais -, alia-se nesse cortejo que cerca as crianças efeminadas para que se possam ratificar cuidados, atenções, em torno a uma reiterado assinalamento de que há algo que deva ser alterado, resolvido, contido: os maneirismos que indiciam os corpos efeminados.

Giancarlo relata de como sua timidez ficava acentuada visto que seu comportamento era socialmente reprovado e passar despercebido, não se submeter ao julgamento alheio, buscando um certo apagamento, invisibilidade, frente aos colegas da escola que assinalavam justamente essa inferiorização de seu corpo tocando-lhe a bunda.

Tornara-se uma criança melancólica, sendo que o que perdera e que não poderia recuperar era a possibilidade de vir a ser heterossexual, não que desejasse se interessar por meninas, mas, sim, acessar os privilégios que os meninos não efeminados acessam. Incluindo,aqui, aqueles que poderiam vir a sentir desejo por outros meninos, não importando a orientação, contanto que se comportassem virilmente.

Um dos momentos marcantes em seu relato e de como contou para sua mãe de seu vazio e sua dor, era véspera de natal, tinha onze anos:

Eu estava sozinho com minha mãe e meu irmão mais novo, Comecei a chorar, chorava, soluçando muito alto. Então eu disse à minha mãe que tinha algo a lhe dizer. E o que eu disse gaguejando foi: 'Mamãe, acho, que os homens chamamminha atenção.' Minha mãe também começou a chorar porque ela entendeu o que eu queria Ihe dizer. (CORNEJO, 2020, p. 87)

Sair do armário envolve uma dinâmica que estabelece uma epistemologia entre o que se sabe e o que se esconde, o que pode vir a ser conhecido e o que não pode ser revelado, o que já se sabe e o que é desconhecido, sendo que se trata de algo por todos já sabido, afinal, ele, com cinco anos, já escutara um "maricón" que Ihe dizia de sua inadequação. Por isso Giancarlo diz de maneira sintética e metafórica o ponto nodal que a questão do "sair do armário" estabelece: "Eu não saí do armário, ela entrou no meu."6

O segredo já sabido por todos é compartilhado na inviabilidade dele vir a ser, de fato, elucidado. O segredo está circunscrito por uma situação paradoxal, pois, por um lado, abundam as inscrições desabonadoras que violentam esses corpos, mas, por outro lado, são essas representações acintosas que, em alguma medida, são mobilizadas na vocalização de si ao se afrontar a norma de gênero7, portanto, não se sai do armário, mas busca-se torná-lo mais habitável, como diz Giancarlo. ${ }^{8}$

6 Eve Sedgwick, em Epistemologia do Armário, 2020, indica os aspectos fantasmáticos que envolvem o estar/sair do armário nos quais não-heterossexuais se veem mobilizados a empreender na modalização do reconhecimento de uma diferença que lhe escapa em alguma medida.

7 Foucault, em História da Sexualidade: a vontade de saber, 1990, chama a atenção de como as tramas discursivas em torno à homossexualidade, em suas espécies e subespécies, ofertaram nomeações que permitiam a esse grupo incorporar e se autonomearem com o intuito de reivindicar legitimidade para sua existência, mesmo que se tratasse, por exemplo, de categorias médicas que os desqualificavam.

8 A história do movimento LBGT é uma expressão do enfrentamento do enxovalho em que - no contexto estadunidense - homofilia, homossexual, 
Essa díade segredo/revelação é movida e movente de uma presença/ausência que se radica em uma vocalização precária de si em que se assinala um lugar no mundo que se entifica através de uma perda irreparável do que não se pode vir a ser. E por isso a melancolia ${ }^{9}$ se apresenta, impossibilitando que o luto dessa perda venha a ser elaborado ao se admitir ser homossexual frente as expectativas da virilidade presumida. ${ }^{10}$

O par segredo/revelação se apresenta marcado por uma borradura, um apagamento derridiano, que, de fato, impossibilita que a saída do armário esgote a violência que o constitui. Essa violência - homofóbica ou gayfóbica ou viadofóbica, caso assim desejarmos - efetiva-se na materialização do armário como condição na qual homens não-heterossexuais se veem marcados por uma diferença em que modaliza-se o "estar" e o "sair". Não havendo posição que não seja tracejada por apagamentos, borraduras, rascunhos em que opera a "dupla força de repetição e de desaparição, de legibilidade e de ilegibilidade". (DERRIDA, 2002, p.221)

Giancarlo elucida esse não lugar ao dizer de sua experiência com quatorze anos quando, na escola, sua bunda deixa de ser golpeada, com o intuito de provocar dor e desprezo, e os toques passam a indicar um desejo, passando a ser bolinada. Mesmo desfrutando dessa proximidade com os outros garotos, principalmente aqueles mais cobiçados por serem fortes e viris, sentindo-se desejado, o que se revela são os condicionantes subalternizadores desse desejo em que a timidez de agora é conivente com as passadas de mão, expressão de um silêncio cúmplice.

Um silêncio marcado por um convite em que o desejo e sua realização expressam distintas possibilidades conforme se localizam, em atos de natureza homoerótica, os ganhos e perdas que envolvem relações assimétricas entre meninos viris e meninos efeminados. Qual o lugar reservado à bicha?

Para Giancarlo:

Houve episódios em que muitos rapazes agarraram minha bunda um após o outro, e eles me mostraram um poder que me faltava antes. Mesmo quando eles me tocavam, mesmo quando me possuíam, havia espaços em mim que eles não podiam mais tocar ou possuir. E se eles fizeram isso foi em termos muito diferentes do que eles esperavam. Eles haviam me humilhado tanto que não podiam mais me humilhar. Eu não precisava mais dizer "pare". Se minha timidez na infância era uma prova de minha incapacidade de dizer "não", naquele glorioso ano de 1999, meu silêncio era uma maneira de aprovar cada passada de mão, de convidá-las a continuar, de desafiá-las a ousar tentar me humilhar, para forçá-los a reconhecer sua falha e sua própria vulnerabilidade.(CORNEJO, 2020, p. 91)

Para outras bichas dependerá o que cada uma possa vir a dizer dessas relações, mas é possível afirmar que as tensões expostas no relato de Giancarlo de alguma maneira assinalam possibilidades de expressão desse não lugar que emerge na busca de um lugar para se estar viada no mundo.

gay ou queer são respostas aos insultos,assim como a própria composição dasigla que se expande conforme novas identidades e pautas insurgem no mundo público a exigir direitos é uma demonstração dessas mobilizações, JIMÉNEZ, 2009, para o Brasil ver GREEN, QUINALHA, CAETANO e FERNANDES, 2018, e TREVISAN, 2000.

9 Butler, em Mecanismos psíquicos del poder, 2001, desenvolve um intricado diálogo entre autores para dizer que o gênero como um efeito ou espécie de melancolia em que, por um lado, via saída do Complexo Freudiano, os meninos são levados a desejarem as mulheres como desaguar de um repúdio ao feminino e proibição da homossexualidade; e, por outro lado, aos meninos homossexuais, resta uma identificação melancólica com o feminino que, efetivamente, "torce" o desejo homossexual sobre si mesmo, gerando culpa.

10Sugerimos a leitura de Homos de Leo Bersani, 1998, em que ele apresenta elementos para pensar essas contradições presentes no ficar/sair do armário.. 


\section{autêntica}

DOI https://doi.org/10.31639/rbpfp.v12i24.341

\section{A escola e a formação moral de professores}

As questões relativas à pluralidade de gênero e de expressões sexuais sempre estiveram e estão presentes nas escolas da Educação Básica, apresentando-se no amplo espectro em que essas expressões possam vir se manifestarno cotidiano escolar e que, inclusive, vem a escapar de nossas lógicas de nomeação bastante restritivas ao pensarmos a diversidade sexual e de gênero.

Diferentes pesquisas apontam o quanto as crianças viadas se encontram expostas à violência na escola. Basta consultarmos o relatório analítico conduzido por José Mazzon (2009), acerca das ações discriminatórias no âmbito escolar, para nos deparamos com dados que demonstram o quanto as crianças não-heterossexuais podem vir a sofrer preconceitos que as tornam potencialmente passíveis de vivenciarem ações discriminatórias de estudantes, funcionários da escola e pais de alunos. ${ }^{11}$

Apenas para trazer alguns desses dados do relatório coletados junto às 501 escolas, 98,5\% dos participantes manifestaram predisposição de manter algum grau de distância em relação a homossexuais; sendo 17,4\% o índice percentual de conhecimento de situações homofóbicas sofridas por alunos e 9,1\% de professores, ou seja, a homofobia está presente nas escolas brasileiras.

Esses dados corroboram que restrita é a nossa capacidade de nomear a diferença posto que, ao representarmos essas variáveis diversas e plurais, fazemos a partir de uma gramática que prescreve não apenas o como nomeamos o que se performa, mas estabelece no ato de nomeação uma hierarquia discricionária do que pode vir a se tornar aceitável e inaceitável, ao que se dá visibilidade e o que se invisibiliza.

Como um ilusionista, o número aqui encenado é bastante sofisticado em sua mediocridade ao reduzir uma ampla possiblidade de expressões a posições restritivas enfaticamente já conhecidas e por nós endossadas de que nos dividimos sexualmente em homens e mulheres e que essa diferença de gênero se funda e se arraiga numa diferença de ordem sexual em que - por vias fisioanatômicas, hormonais, gonadais, cromossômicas - sexo e gênero se alinhariam não apenas na definição de que há um sexo correspondente a um gênero, em uma dualidade previsível, mas que essa dualidade ainda se cauciona no reconhecimento de que esses corpos se reconhecem como heterossexuais.

Nós, professores e professoras, gestores, coordenadores pedagógicos, todos e todas que cotidianamente estamos na Educação Básica, temos que nos perguntar sobre o que podemos fazer frente a verdades que nos trespassam e nos mobilizam na manutenção de uma ordem excludente.

Uma das questões que mais nos chama a atenção na manutenção dessa ordem excludente é como os sistemas de ensino estatais, ao irem se organizando na virada do século XIX para o século XX, vão paulatinamente constituindo as regulações profissionais que organizam a inserção desses sujeitos no chão da escola.

Julia Varela e Fernando Alvarez Uria (1992, p. 69), indicam, sumariamente, por um lado, como se dá a "definição de um estatuto da infância"; e, por outro lado, o "aparecimento de um corpo de especialistas da infância dotado de tecnologias específicas e de 'elaborados' códigos teóricos". Isso em um contexto no qual a escola torna-se um "espaço específico destinado à educação das crianças", em que "outros modos de educação" são extintos para que se institucionalize a compulsoriedade da educação escolar estatal, universal, gratuita e laica.

11 Há outras pesquisas que caminham na mesma direção, como as executadas durante as Paradas LGBTQIA+, conferir em CARRARAet ali 2005,2006 e 2007; FACCHINI, 2007; e PRADO, 2006. 
Junto a esses "elaborados códigos teóricos", constitui-se um conjunto de normas e de valores, entre os docentes, fortemente influenciado por crenças e atitudes morais e religiosas que subsistem a profissionalização e a estatização da profissão e, portanto, mesmo com apresumida adesão dos sistemas de ensino a princípios morais laicos, a escola e seus profissionais orientam seus valores por normas religiosas de conduta.

Segundo Nóvoa:

A princípio, os professores aderem a uma ética e a um sistema normativo essencialmente religioso; mas, mesmo quando a missão de educar é substituída pela prática de um ofício e a vocação cede o lugar à profissão, as motivações originais não desaparecem. Os professores nunca procederam à codificação formal das regras deontológicas, o que se explica pelo facto de lhes terem sido impostas do exterior, primeiro pela Igreja e depois pelo Estado, instituições mediadoras das relações internas e externas da profissão docente. E, no entanto, é incontestável que os professores integraram este discurso, transformando-o num objetopróprio: nas décadas de viragem do século XIX para o século XX, a época dos Congressos dos Professores, que constituíram verdadeiros "laboratórios de valores comuns", sente-se a perpetuação de um ideário colectivo onde continuam presentes as origens religiosas da profissão docente. (NÓVOA, 1991, p. 13)

O que nos indica que, nas franjas da laicidade incorporada pelo discurso da escola republicana, em que se pleiteava a substituição de uma moral religiosa por uma moral laica e cívica, vários aspectos que atravessam a criação das regras deontológicas condizentes com a profissionalização da docência não sofreram essa inflexão modernizadora a ponto de romper com uma moral religiosa de caráter conservador,

É importante lembrar, entretanto, que esse aspecto moral não entra em contradição com um dos princípios da escola republicana, como anunciado por Durkheim, em que se utiliza dos universais homogeneizadores da escolarização republicana para pleitear a dessexualização dos corpos em que os alunos e alunas são vistos como seres incorpóreos nomeados como "as crianças".

Essa pretensa homogeneização e dessexualização faz parte das condições discursiva em que se tecem os exercícios da docência em sua vocalização das práticas pedagógicas quando são interpelados sobre os fundamentos que organizam as regras deontológicas da profissão. Sob esse discurso simulado e hipotético, entretanto, abrigam-se as desigualdades sociais que se produzem e reproduzem em meios escolares como o racismo, o sexismo, a homofobia, entre outros.

Mas é nessa convergência de uma moral religiosa e corpos assexuados em que sãomarcadas a inserção da docência em seu exercício profissional. Tracejando um movimento no qual os professores mobilizam um discurso em que se apresentam na escola como despidos de sexualidades, assim como advogam ver a seus alunos e alunas como assexuados, ao mesmo tempo em que cultivam uma autoimagem aparente de serem moralmente corretos, segundo os cânones do heterosexismo, portadores de uma vida sexual exemplar em sua vida fora da escola.

Ao mesmo tempo, os professores levam uma vida sexual "exemplar" fora da escola e assim se espera que o façam. "Exemplar" significa, nesse contexto, que o ideal é ser heterossexual, estar casado e, no caso das mulheres, ter filhos já em idade escolar. Dentro da escola, a identidade sexual dos professores se vincula ao papel do "guardião moral", que serve de exemplo para das crianças e regula a sexualidade dos jovens. E quando os docentes questionam ou rechaçam este papel de "guardião moral", é possível que sua vida se converta em motivo de escândalo, inclusive de pânico moral. (EPSTEIN e JOHNSON, 2000, p. 137 -138) 
Philippe Perrenoud $(2001,163)$ enfrenta esse debate a partir de outro ponto de vista e, ao retomar o conceito de habitus de Pierre Bourdieu, propõe analisar os condicionantes das práticas docentes, enfatizando que parte significativa "da ação pedagógica apoia-se em rotinas ou em uma improvisação regrada, que evocam mais um habitus pessoal ou profissional do que saberes".

Sendo assim, a hegemonia de perspectivas heterocentradas, em que se naturalizam posições heterossexuais e se estigmatizam as posições dissidentes, corresponderia às estruturas nas quais os professores foram socializados e que, via socialização, tornaram-se disposições subjetivas mobilizadas por eles em contextos escolares.

O sentido de uma pergunta, de uma resposta, de um erro, depende da pessoa da qual emanam, de grupos (família, sexo, classe social, comunidade linguística, confessional ou ética) dos quais é originária, bem como de relações que o professor mantém com essa pessoa e os grupos a que pertence. PERRENOUD (2001, p. 167)

O que nos coloca diante de várias questões posto que, como afirma Mireille Cifali (2001, 105), "Nada nos protege de uma derrapagem, por si e pelo outro. (...) Quando uma situação faz eclodir nossas referências conscientes, logo pensamos em nos proteger em nossas clivagens, repetições e cenários imaginários." $\mathrm{E}$ são nesses cenários imaginário sem que são mobilizados, através da insurgência da díade amor e ódio a que se refere Cifali, os ambientes em que se proliferam imagens associadas a boa e a má sexualidade.

Esses dois autores, entretanto, buscam ampliar o repertório dos docentes ao trazer a cena, por um lado, segundo Perrenoud, o aporte de vias, através de diferentes estratégias formativas, para a tomada de consciência e transformação de esquemas dos habitus que organizam a docência; e, por outro lado, segundo Cifali, deve-se permitir o exercício de uma inteligência clinica que interatue com os diferentes saberes experimentais que insurgem na relação com o outro.

É endereçado aos docentes, portanto, que eles reconheçam a presença das crianças viadas e, em consequência, reconheçam-se no que essas crianças aportam.

\section{As crianças viadas interpelam a docência}

Analisar esse conjunto de questões e nos dispor a enfrentá-las exige que tomemos alguns cuidados para que não a reinscrevamos justamente nos aspectos duramente criticados por Eve Sedgwick e Giancarlo Cornejo, quais sejam,abordá-las a partir de um viés psicologizante em que se perderiam os liames políticos que sustentam um enfrentamento mais consequente que permitiria tornar a escola um ambiente mais seguro para todos e todas.

O enfrentamento das hierarquias de gênero exige que nos atentemos para as estruturas que estruturam e são estruturadas pelas normas de gênero em que se expressam e se assentam as lógicas de exclusão e subalternização das crianças viadas.

O primeiro aspecto é reconhecer que, como nos diz Judith Butler:

Como em outros dramas sociais rituais, a ação do gênero requer uma performance repetida. Essa repetição é a um só tempo reencenação e nova experiência de um conjunto de significados já estabelecidos socialmente; e também é a forma mundana e ritualizada de sua legitimação. Embora 


\title{
autêntica
}

DOI https://doi.org/10.31639/rbpfp.v12i24.341

\begin{abstract}
existam corpos individuais que encenam essas significações estilizando-se em formas do gênero, essa "ação" é uma ação pública. Essas ações têm dimensões temporais e coletivas, e seu caráter público não deixa de ter consequências; na verdade, a performance é realizada com o objetivo estratégico de manter o gênero em sua estrutura binária - um objetivo que não pode ser atribuído a um sujeito, devendo, ao invés disso, ser compreendido como fundador e consolidador do sujeito. (BUTLER, 2003, p. 200).
\end{abstract}

Assim, masculinidades e feminilidades - além de serem construções sociaispassíveis de serem apreendidas a partir dos relatos de natureza antropológica e histórica - são também significantes que, ao serem dispostos de maneira binária, viabilizam o que estabelecemos como válido e adequado: macho/homem/masculino e fêmea/mulher/feminino emparelham-se, via reiteração ad nauseam, "a serviço da consolidação do imperativo heterossexual".

"(...) as normas regulatórias do "sexo" trabalham de uma forma performativa para constituir a materialidade dos corpos e, mais especificamente, para materializar o sexo do corpo, para materializar a diferença sexual a serviço da consolidação do imperativo heterossexual. (BUTLER, 1999, p.154)

Tratar-se-ia de uma narrativa produzida, submetida a determinados condicionantes, que, inclusive, materializam o sexo do corpo, entificando a diferença sexual no qual se organiza o binarismo, em pares complementares, justapondo a ideia de sexo oposto, impedindo que venham a ser estabelecidas outras inteligibilidades para o que se nomeia como adequado ao gênero - como são as crianças viadas.

Nesse sentido, o segundo aspecto a ser reconhecido, portanto, é que se tratariam de relações de poder que engendram essa dimensão performática de gênero ao naturalizarem, como dadas, certas posições, enquanto tornam bizarras a outras.

Diz-nos Foucault:

Daí os dispositivos de saturação sexual, tão característicos do espaço e dos ritos sociais do século XIX. Diz-se, frequentemente, que a sociedade moderna tentou reduzir a sexualidade ao casal - ao casal heterossexual e, se possível, legítimo. Poder-se-ia também dizer que ela inventou, ou pelo menos organizou, cuidadosamente e fez proliferar, grupos com elementos múltiplos cuidadosamente e sexualidade circulante: uma distribuição de pontos de poder hierarquizados ou nivelados, uma "busca" de prazeres - no duplo sentido de desejados e perseguidos; sexualidades parcelares toleradas ou encorajadas; proximidades que se apresentam como procedimentos de vigilância e funcionam como mecanismos de intensificação; contatos indutores. (FOUCAULT, 1990a, p. 45 - 46)

Estabelecem-se as perpétuas espirais de poder e prazer, em que se indicia o que é tolerado ou encorajado, o que, segundo Butler, está no cerne de suas postulações de que gênero é expressão de uma composição performativa, não havendo identidades preexistentes, não havendo atos de gênero verdadeiros ou falsos e que "a postulação de uma identidade de gênero verdadeira se revelaria uma ficção regulatória".

A possibilidade de retermos e nomearmos alguma identidade de gênero como adequada já é tomarmos uma posição valorativa e, portanto, instaurarmos uma realidade ontológica fundacional e essencialista sobre o que entendemos por gênero. Ou seja, ao obliteramos uma concepção de gênero como performance, centramos nossos esforços na regulação de gênero prevista e prescrita normativamente em que se torna crível uma 


\section{autêntica}

DOI https://doi.org/10.31639/rbpfp.v12i24.341

diagramação na qual encontraria um regime de verdade a validar e falsear algumas performances indicando originalidades e algumas inadequações.

E aqui se instaura o terceiro aspecto destacado por Judith Butler sobre as relações de gênero e de como postularmos gênero como atos performativos nos permite interpelar as variáveis estilísticas em jogo a partir de uma lógica diferencialista.

Esse é o aspecto central nas teorizações de Butler visto que admitir a dimensão construtivista das performances e as relações de poder que as permeiam são insuficientes para compreender a arquitetura conceitual de Problemas de gênero. Insuficiência que, inclusive, retira o potencial subversivo de sua teorização por esvaziar o conceito de performance justamente do aporte disruptivo que incide sobre as identidades de gênero como indicado no subtítulo da obra - Feminismo e subversão da identidade.

Por um lado, são as relações de poder e as violências por elas veiculadas que buscam marcar os corpos e fixá-los em uma hierarquia de gênero, em que performar gênero é se submeter às normas de gênero em que as identidades encontram-se prescritas. Mas, por outro lado, não basta reconhecer o caráter modelador das identidades, sob o risco de nos determos na reiteração das normas de gênero e sua materialização das violências simbólicas, posto que o caráter performativo que Butler atribui ao gênero não se restringe apenas em operacionalizar a norma, mas de interpelá-la e promover deslocamentos significativos em suas inscrições generificantes.

O esforço intelectual de Butler é, justamente, romper com o caráter existencialista que esteia as perspectivas construtivistas que iriam ao encontro às críticas elaboradas por Sedgwick e Cornejo quando denunciam os dispositivos médicos e psi, assim como os pedagógicos, de psicologizarem a diferença por a individualizarem - tratar-se-ia da criança, em que se encarnaria a diferença, como portadora de uma alteridade singular oposta e especular à identidade mestra, as crianças viadas no reino da heterolândia.

O que Butler recupera é a dimensão politica ao dizer que as identidades de gênero não são apenas encarnações singulares posto que, "Embora existam corpos individuais que encenam essas significações estilizando-se em formas do gênero, essa 'ação' é uma ação pública."

Essa pode vir a se tornar uma ação política, uma ação que se apresenta inserida no jogo diferencial da linguagem em que a identidade é interpelada não por seu caráter oposicional, portanto binário, mas em seus rebatimentos entre o que incorpora como positividade e renega como negatividade ou, brincando com as palavras, incorpora como negatividade e renega como positividade.

Ou nas palavras de Butler:

Na verdade, a construção do gênero atua através de meios excludentes de forma que o humano é produzido sobre e contra o inumano, mas através de um conjunto de exclusões, de apagamentos radicais, os quais, estritamente falando, recusam a possibilidade de articulação cultural. Portanto, não é suficiente afirmar que os sujeitos humanos são construídos, pois a construção do humano é uma operação diferencial que produz o mais e o menos "humano", o inumano, o humanamente impensável. Esses locais excluídos vêm a limitar o "humano" com seu exterior constitutivo, e a assombrar aquelas fronteiras com a persistente possibilidade de sua perturbação e rearticulação. 


\section{autêntica}

DOI https://doi.org/10.31639/rbpfp.v12i24.341

Paradoxalmente, a investigação sobre os tipos de apagamento e exclusões pelos quais a construção do sujeito atua não é mais construcionismo, mas também não é essencialismo. Pois existe um "exterior" relativamente àquilo que é construído pelo discurso, mas não se trata de um "exterior" absoluto, um lá ontológico que excede ou contraria a as fronteiras do discurso; como um "exterior" constitutivo ele é aquilo que pode apenas ser pensado - quando pode - em relação àquele discurso, nas suas - e com as suas - mais tênues fronteiras. (BUTLER, 1999, p. 161- 162)

O outro constitutivo nos permite pensar de como as dissidências de gênero, entre elas, as crianças viadas, ao se erigirem na fronteira estabelecidas pelas normas de gênero, ao se verem assinaladas como menos humanas, poderão, por um lado, terem suas performances compreendidas a partir dos construtos heterossexuais em que o "efeminamento/efeminização" de seus atos é indício de sua desumanização; ou, por outro lado, poderá vir a representar o lugar da desnaturalização da fronteira ao permitir deslocamentos em que ser criança viada seja a afirmação de si em sua humanidade possível.

O que nos permite dizer que a primeira possibilidade reitera que as crianças viadas copiam os maneirismos das mulheres, pressupondo que tratar-se-ia da cópia de um original no qual se essencializa a mulher; a segunda possibilidade nos diz que, como não há nenhuma originalidade, tratar-se-ia de uma cópia da cópia, condição sinequanon de toda performance de gênero.

Ou seja, é nesse confronto de significação que os professores devem se perguntar não apenas a qual nomeação irão apelar ao se referirem a lago ou Giancalo, mas o que essa nomeação convoca nas normas de gênero e, o que é mais importante, como essa mobilização interpela a cada um e a todos.

Afinal, se a norma é marcada por inclusões e exclusões, como podemos tornar público outras possibilidades de afirmação do humano e como se engendram a cada casoas fronteiras, ainda que precárias, entre os "humanos", os inumanos e os inumanamente impensáveis?

Como operar nesse campo de possíveis frente às premências que permeiam a ação pedagógica a que nos chama atenção Perrenoud ao tratar das configurações que poderão vir assumir a docência em contextos de gestão da urgência e de improvisações regradas? 


\section{autêntica}

DOI https://doi.org/10.31639/rbpfp.v12i24.341

\section{À guisa de conclusão}

As questões aqui apontadas giram em torno da criança viada, mas não se prendem apenas a essas crianças posto que elas nomeiam estruturas de regulação em que nos movemos e nos reconhecemos em algum ponto do debate proposto.

Avançar nessa discussão exige que rompamos ideias bastante comuns nas escolas:a primeira de que a função da escola é homogeneizar os estudantes postos que na escola não há meninos e meninas, mas, sim estudantes incorpóreos, sem sexo, sem gênero; a segunda é de que os modelos de gênero a serem reproduzidos na escola e seus profissionais devem ser os hegemônicos por se tratar de modelos em que há maior adesão por parte de todos quando pensamos que é a partir desses modelos que organizamos nossa experiência.

Esses dois pontos, apesar de aparentemente se distinguirem, confundem-se no chão da escola em que a neutralidade é o outro nome que atribuímos a manutenção do status quo quando pensamos em relações de gênero e expressões da sexualidade.

Basta fazermos uma observação em seu cotidiano para percebermos que, em nome da neutralidade, afirmam-se constantemente as perspectivas heterocentradasem sua organização em que determinadas posições, por serem tão naturalizadas, não são questionadas por professores e demais profissionais da escola.

Há o medo que discutir outras possibilidades, para além dessa matriz, é incentivar a homossexualidade, quando se trata de combater a homofobia, não apenas enquanto ódio ou aversão a quem é ou se reconhece homossexual ou os não-heterossexuais, mas, como nos diz Welzer-Lang, tratar-se-ia da homofobia como vigilância de gênero, afinal não se trata de orientação sexual, mas de identidade de gênero como alertado por Sedgwuick, Gincarlo e as crianças viadas.

Nós, professores e professoras - assim como os demais educadores e profissionais da educação, envolvendo a coordenação, gestão, cantineiras, vigilantes, bibliotecários - aos nos aproximarmos dessas questões, devemos nos despir dessas ilusões de que as crianças são incorpóreas e encararmos que a reprodução da matriz heterossexista é a manutenção de violências de gêneros que reiteram a LBGTfobia, o machismo e o sexismo.

Nessa tarefa, é necessário, romper compreensões de que nós somos assexuados e desnaturalizar que também vivemos o que essa matriz prescreve como expressões modelares da heterossexualidade enquanto prescrições restritivas sobre a masculinidade e a feminilidade.

Não se trata de uma tarefa fácil, mas necessária se nos dispormos a reconhecer a humanidade das crianças viadas para que, talvez, a morte de lago não tenha sido em vão. 


\section{autêntica}

DOI https://doi.org/10.31639/rbpfp.v12i24.341

\section{Referências}

BERSANI. Leo. Homos. Buenos Aires: Editora Manantial. 1998, p. 206.

BUTLER, Judit. Corpos que pesam: sobre os limites discursivos do "sexo". In.: LOURO: Guacira. (org.) O corpo Educado: pedagogias da sexualidade. 1999, p. 176.

BUTLER, Judith. Mecanismos psíquicos del poder: teorías sobre la sujeción. Madrid: Ediciones Cátedra, 2001, p. 213.

BUTLER, Judith. Problemas de gênero: feminismo e subversão da identidade. Rio de Janeiro: CivilizaçãoBrasileira, 2003. 236 p.

BUTLER, Judith. Vida precaria: el poder del duelo y laviolencia. Buenos Aires: Paidós, 2009. p.192.

CARRARA, Sérgio. et alii. Política, direitos, violência e homossexualidade: pesquisa $9^{a}$ parada do orgulho GLBT - Rio 2004. Rio de Janeiro: CEPESC, 2005, p. 120.

Carrara, Sérgio. et alii. Política, direitos, violência e homossexualidade. pesquisa $5^{\mathrm{a}}$ parada da diversidade Pernambuco 2006. Rio de Janeiro: CEPESC, 2007, p. 90.

CARRARA, Sérgio. et alii.; Política, direitos, violência e homossexualidade: pesquisa. $9^{a}$ parada do orgulho GLBT. São Paulo 2005; Rio de Janeiro : CEPESC, 2006, p. 80.

CIFALI, Mireille. Conduta Clinica, Formação e Escrita. In.: PAQUAY, Léopold; PERRENOUD Philippe; ALTET, Marguerite; CHARLIER, Evelyne. (orgs)Formando professores profisionais: Quais estratégias? Quais competências? Porto Alegre: Artmed Editora, 2001, 103 - 117p.

CORNEJO, Giancarlo. La guerra declarada contra elniño afeminado: uma autoetnografia "queer". Disponível em https://revistas.flacsoandes.edu.ec/iconos/article/view/747/727. Visualizado em: 29 abr. 2020.

DERRIDA, Jacques. A escritura e a diferença. São Paulo: Editora Perspectiva. 2002, p. 252.

EPSTEIN, Débora; JOHNSON, Richard. Sexualidades e institución escolar. Madrid: EdicionesMorata; Coruña: Ediciones Paideia. 2000, p. 231.

ERIBON, Didier. Reflexões sobre a questão gay. Rio de Janeiro: Companhia de Freud, 2008. 445p.

FACCHINI, Regina. et alii . Sexualidade, cidadania e homofobia: pesquisa $10^{a}$ parada do orgulho GLBT de São Paulo - 2006. São Paulo: APOGLBT, 2007, p. 95.

FOUCAULT, Michel. História da sexualidade: a vontade de saber. Rio de Janeiro: Graal, 10ª ed., 1990a, p. 152.

FOUCAULT, Michel. História da sexualidade: o uso dos prazeres. Rio de Janeiro: Graal, 6a ed., 1990b, p. 232.

GREEN, James; QUINALHA, Renan; CAETANO, Márcio; FERNANDES, Marisa; (orgs) Historia do movimento LGBT no Brasil. São Paulo: Alameda. 2018. p. 536. 


\section{autêntica}

DOI https://doi.org/10.31639/rbpfp.v12i24.341

HALPERIN, David. How to do the History of Homosexuality. Chicago/London: The Universityof Chicago Press. 2002, p. 208.

HESS. Remi. La socianalyse. Paris: EditionsUniversitaires. 1975, 113p.

JIMENEZ, Rafael; Manifiestos gays, lesbianos, y queer: testimonios de uma lucha (1969 - 1994), Barcelona: Icaria. 2009. p.268.

MAZZON, José Afonso. Projeto de estudo sobre ações discriminatórias no âmbito escolar, organizadas de acordo com áreas temáticas, a saber, étnico-racial, gênero, geracional, territorial, necessidades especiais, socioeconômica e orientação sexual: relatório analítico final. São Paulo: FIPE, Brasília: MEC:INEP, 2009, p. 91.

NÓVOA, António. O Passado e o presente dos professores. In.: NÓVOA, António. (org.) Profissão professor. Porto: Porto Editora. 1991. 11 - 32p.

PERRENOUD, Philippe. O trabalho sobre o habitus na formação de professores: análise das práticas e tomadas de consciência. In.: PAQUAY, Léopold; PERRENOUD Philippe; ALTET, Marguerite; CHARLIER, Evelyne. (orgs)Formando professores profisionais: Quais estratégias? Quais competências?Porto Alegre: Artmed Editora, 2001, $161-184 p$.

PRADO, Marco. et alii. Participação, política e homossexualidade: $8^{a}$ ParadaGLBT de Belo Horizonte BeloHorizonte: Prefeitura Municipal de Belo Horizonte, 2006, p. 86.

SEDGWICK, Eve. "How to Bring Your Kids Up Gay". In WARNER. Michael. (org.) Fear of a Queer Planet: Queer Politics and Social Theory. Minneapolis / London: University of Minnesota Press, 1993, p. 69-81p.

SEDGWICK, Eve. Epistemologia do armário. Disponível em https://www.scielo.br/pdf/cpa/n28/03.pdf. Visualizado em 4 de maio de 2020.

TREVISAN, João Silvério. Devassos no paraíso. 3. ed. rev. e ampl. Rio de Janeiro: Record, 2000. p.586.

VARELA, Julia; URIA, Fernando Alvarez; A maquinaria escolar, In.: Teoria e Educação. Porto Alegre: Pannonica Editora. $n^{\circ}$ 6. 1992. 6896 p.

WELZER-LANG, Daniel. A construção do masculino: dominação das mulheres e homofobia. Disponível em http://www.scielo.br/pdf/ref/v9n2/8635.pdf. Visualizado em: 29 abr. 2020.

WINKLER, John. Lascoaccionesdeldeseo: antropologia del sexo y el gênero em laantiguaGrecia. Buenos Aires: Manantial. 1994, p. 307.

NOGUEIRA, P. H. Q.; Quando as crianças viadas interpelam a docência. Formação Docente - Revista Brasileira de Pesquisa sobre Formação de Professores. Belo Horizonte. Vol. 12, nº. 24 (p. 105-120) 31 ago. 2020 